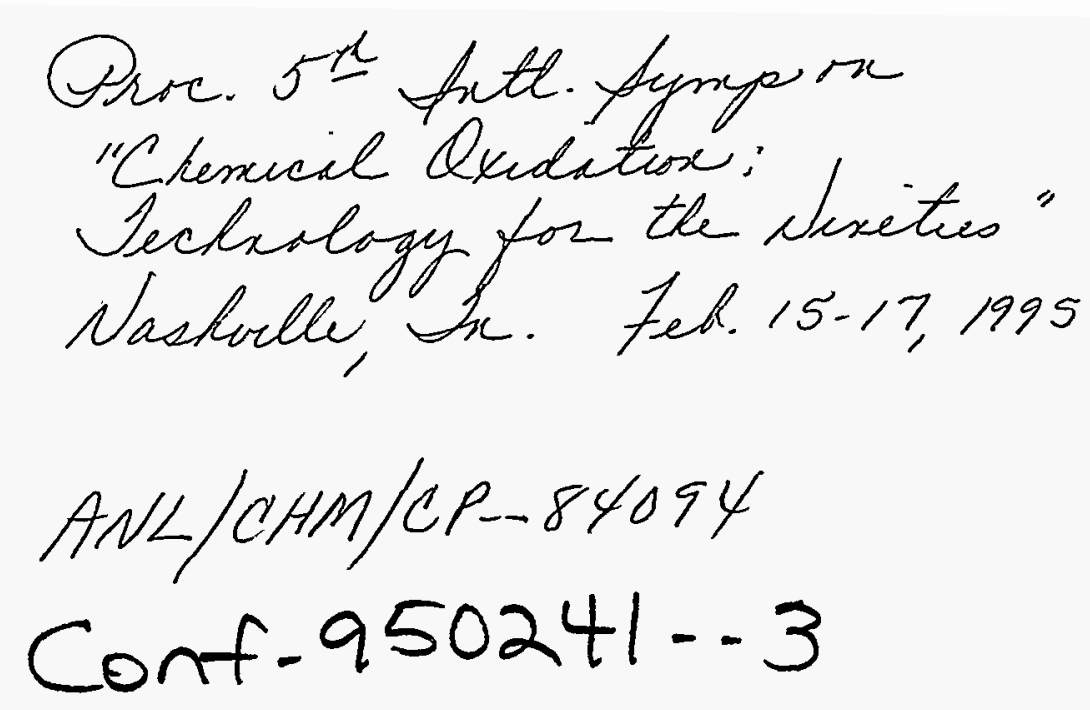

\title{
Conversion of Holes into Reducing Species on Surface Modified Small-particle $\mathrm{TiO}_{2}$
}

\author{
O.I. Micic ${ }^{*}$, A.E. Ostafin, T. Raih, J.J. Sabelko**, M.C. Thurnauer, D.M. Tiede, \\ Y. Zhang***
}

Chemistry Division, Argonne National Laboratory, Argonne, Il 60439

\section{DISCLAIMER}

This report was prepared as an account of work sponsored by an agency of the United States Government. Neither the United States Government nor any agency thereof, nor any of their employees, makes any warranty, express or implied, or assumes any legal liability or responsibility for the accuracy, completeness, or usefulness of any information, apparatus, product, or process disclosed, or represents that its use would not infringe privately owned rights. Reference herein to any specific commercial product, process, or service by trade name, trademark, manufacturer, or otherwise does not necessarily constitute or imply its endorsement, recommendation, or favoring by the United States Government or any agency thereof. The views and opinions of authors expressed herein do not necessarily state or reflect those of the United States Government or any agency thereof.

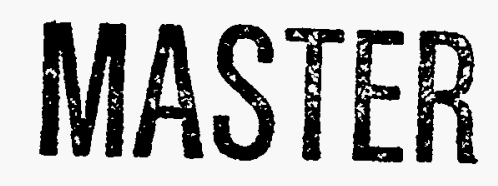




\section{DISCLAIMER}

Portions of this document may be illegible in electronic image products. Images are produced from the best available original document. 


\begin{abstract}
Complexation of colloidal titanium dioxide nanoparticles ( $40 \AA$ ) by cysteine as a surface derivative was investigated by electron paramagnetic resonance (EPR) and infra-red (defusion reflectance infra-red Fourier Transform - DRIFT) spectroscopies. It was found that cysteine strongly binds to the colloid surface. We have demonstrated with EPR spectroscopy that cysteine modifies the $\mathrm{TiO}_{2}$ surface with formation of new trapping sites where photogenerated electrons and holes are localized. Illumination of cysteine modified $\mathrm{TiO}_{2}$ at $77 \mathrm{~K}$ resulted in formation of a sulfur centered radical observed by EPR spectroscopy at $200 \mathrm{~K}$. Upon addition of lead ions, a new complex of cysteine that bridges surface titanium atoms and lead ions was detected by $\mathbb{R}$ spectroscopy. Illumination of lead/cysteine modified $\mathrm{TiO}_{2}$ did not result in the formation of sulfur centered radical, but symmetrical, lattice defect type EPR signal for trapped holes was observed. However, addition of methanol to this system resulted in the formation of $\cdot \mathrm{CH}_{2} \mathrm{OH}$ radical following illumination at $8.2 \mathrm{~K}$. After the temperature was raised to $120 \mathrm{~K}$, doubling of the signal associated with electrons trapped at particle surface (Ti(III) $\left.)_{\text {surf }}\right)$ was observed. On further increase of the temperature to $200 \mathrm{~K}$ the EPR signal for trapped electrons disappeared as a result of the reduction of $\mathrm{Pb}^{2+}$ ions, and metallic lead was observed to precipitate. Conversion of photogenerated holes into trapped electrons due to the presence of methanol doubles the yield of trapped electrons that can reduce $\mathrm{Pb}^{2+}$. Direct reduction of $\mathrm{Pb}^{2+}$ ions by $\cdot \mathrm{CH}_{2} \mathrm{OH}$ radical on $\mathrm{TiO}_{2}$ was not detected.
\end{abstract}

\title{
INTRODUCTION
}

\section{Sources of heavy metals}

In the last ten years extensive studies of methods for the removal of organic and inorganic environmental contaminants from waste water streams have been undertaken. ${ }^{1-3}$ Industrial activities release many toxic agents into the environment and ground-waters become charged with toxic agents. Heavy metals are the main pollutant in the waste and ground waters at metallurgical installations. ${ }^{4}$ The geological equilibrium becomes disturbed by releasing large

\footnotetext{
* Present address National Renewable Energy Laboratory, Golden, Colorado.

** Undergraduate Research Participant, 1994.

*** Present address University of Wisconsin, Department of Medical Physics, Madison, WI.
} 
quantities of heavy metals $(\mathrm{Pb}, \mathrm{Cd}$ and $\mathrm{Hg}$ ) from immobilized minerals and ores. Moreover, lead is also a component of insecticides, paint, water pipes, automobile exhaust and used motor oils. Consequently these sources contribute to contamination of soil and waters with lead ions. 56

Heavy metal ions $\left(\mathrm{Pb}^{2+}\right.$ and $\left.\mathrm{Cd}^{2+}\right)$ are not biodegradable, they have long lifetimes and cannot be detoxified by chemical means. Their removal from aquatic media requires a one electron transfer process having a very negative reduction potential $\left(\mathrm{E}^{\mathrm{O}}\left(\mathrm{Pb}^{2+} / \mathrm{Pb}^{+}\right)=-1.0 \mathrm{~V}\right.$ vs. $\mathrm{NHE}$ and $\mathrm{E}^{\circ}\left(\mathrm{Cd}^{2+} / \mathrm{Cd}^{+}\right)=-1.9 \mathrm{~V}$ vs NHE $)$, thus eliminating a majority of conventional homogeneous chemical means for removal. However in heterogeneous systems where multiple charges can be injected simultaneously, the one electron step can be bypassed and the potential for removal of heavy metals can be lowered.

\section{Semiconductor Assisted Photocatalysis}

Semiconductor assisted photocatalysis provides a method of photoelectrochemical removal of heavy metals from aqueous media. Particulate semiconductor materials behave as microelectrodes that consist of cathodic and anodic parts. These materials have proven to be excellent light harvesting materials and mediators in the photochemical degradation of several environmental contaminants. ${ }^{1-3}$ The principle behind semiconductor $\left(\mathrm{TiO}_{2}\right)$ assisted photocatalysis involves the photoexcitation of the semiconductor with light energy greater than the particle band gap which is followed by generation of electron /hole pairs:

$$
\mathrm{TiO}_{2} \rightarrow \mathrm{e}_{\mathrm{cb}}^{-}\left(\mathrm{TiO}_{2}\right)+\mathrm{h}^{+}{ }_{\mathrm{vb}}\left(\mathrm{TiO}_{2}\right)
$$

where hv signifies photoexcitation, $\mathrm{e}_{\mathrm{cb}}^{-}$and $\mathrm{h}^{+} \mathrm{vb}$ are the electrons and holes produced in the conduction and valence band of a semiconductor, respectively. The electrons and holes can diffuse to the semiconductor particle surface and can be exploited for various redox processes analogous to the microelectrochemical cell. As the charge carriers created on illuminated semiconductor are trapped at the surface, and the redox reactions occur at the solid/solution interface, the surface of the particles plays an important role in electron/hole transfer reactions and can be engineered to improve both light harvesting and/or redox characteristics of a semiconductor.

Application of the semiconductor assisted photocatalysis is primarily focused on $\mathrm{TiO}_{2}$ which is a nontoxic, durable semiconductor that has been shown to be useful for the oxidative destruction of the most resistant organic compounds.such as polychlorinated aromatics 8 or those prevalent in oil-spills, ${ }^{9}$ and for reduction of several heavy metals $\left(\mathrm{Hg}^{2+}, \mathrm{Pt}^{4+}, \mathrm{Au}^{4+}, \mathrm{Rh}^{4+}\right.$. These principles have found extensive application in the field of organic phototransformation ${ }^{10}$ and only recently in environmental chemistry and pollutant abatement. ${ }^{1-3}$ The advantage of these systems is the potential for accumulation of charges on the particle surface results in simultaneous injection of multiple charges, if a suitable scavenger of the other charge is present at the surface. However, the reduction of very toxic heavy metal ions such as $\mathrm{Pb}^{2+}$ or $\mathrm{Cd}^{2+}$ with negative redox potential of the first one electron transfer process was not reported in aerated or deaerated aqueous suspensions of $\mathrm{TiO}_{2}$. The removal of lead ions on platinized titanium oxide by oxidation to $\mathrm{PbO}_{2}$ in oxygen saturated solutions was previously reported by Lawless et al. ${ }^{11}$ The authors suggested that the lead ions were both partially reduced on platinum islands (on $\mathrm{TiO}_{2}$ particle surface) and oxidized into $\mathrm{PbO}_{2}$. However, Tanaka et al. ${ }^{12}$ have reported only oxidation of lead ions on platinum loaded $\mathrm{TiO}_{2}$ suspensions. when the conduction band electrons reduce oxygen or protons in the solution. Selective metal deposition has been of interest for 
applications such as metal extraction processes in the mining industry or metal recovery from waste water streams.

Here we report that modification of the surface of small particle $\mathrm{TiO}_{2}$ results in enhanced reduction properties of conduction band electrons. The interfacial charge transfer processes in surface modified $\mathrm{TiO}_{2}$ colloids and the mechanism of the current doubling process in the presence of methanol, i.e., the conversion of photogenerated holes into trapped electrons, were investigated by EPR spectroscopy. We have applied the semiconductor assisted photocatalysis to remove lead and mercury ions from aqueous solutions with both photogenerated electrons and holes.

\section{EXPERIMENTAL}

All the chemicals were reagent grade and used without further purification (Aldrich or Baker). $\mathrm{P} 25 \mathrm{TiO}_{2}$ Degussa powder was a generous gift by the Degussa Corp. Triply distilled water was used. The $\mathrm{pH}$ was adjusted at $\mathrm{pH} 4$ with $\mathrm{NaOH}$ or HCl. Oxygen was removed by bubbling with argon.

UV-vis absorption spectra were recorded on a Shimadzu UV-100 instrument. Colloidal TiO2 was prepared using the procedure described elsewhere. ${ }^{13}$ The concentration of $\mathrm{TiO}_{2}(0.1-$ $0.6 \mathrm{M}$ ) was determined from the concentration of the peroxide complex obtained after dissolving the colloid in concentrated $\mathrm{H}_{2} \mathrm{SO}_{4} \cdot{ }^{14}$ The dark brownish-gray precipitate obtained after steady state illumination was oxidized by hydrogen peroxide $\left(\mathrm{E}^{\circ}\left(\mathrm{H}_{2} \mathrm{O}_{2} / \mathrm{OH}^{-}\right)=0.88 \mathrm{~V}\right)$ with formation of colorless $\mathrm{Pb}^{2+}$, meanwhile addition of sodium boron hydride $\left(\mathrm{E}^{\mathrm{C}}\left(\mathrm{NaBH}_{4} / \mathrm{NaBH}_{3}, \mathrm{H}\right)=-\right.$ $0.827 \mathrm{~V}$ ) did not affect the precipitate. It should be noted that addition of sodium boron hydride to the solution of $\mathrm{Pb}^{2+}$ ions in the presence of $\mathrm{TiO}_{2}$ did not produce metallic lead.

Apparatus EPR: Colloidal solutions were degassed with nitrogen and sealed in quartz EPR tubes. Samples were excited at $77 \mathrm{~K}$ by a Questek 2400 excimer laser ( $308 \mathrm{~nm}, 120,5$, and $0.2 \mathrm{~mJ} / \mathrm{pulse} ; 3000$ pulses) After laser irradiation, the samples were transfered to a variable temperature dewar mounted in the EPR spectrometer (Varian E-9). Samples were checked for background EPR signals before irradiation. The $\mathrm{g}$ factors were calibrated by comparison to a powder 1,1-diphenyl-2-picrylhydrazyl (DPPH) radical sample ( $g=2.0037 \pm 0.0002)$. Lead ions were added as $\mathrm{Pb}\left(\mathrm{CH}_{3} \mathrm{COOH}\right)_{2}$. FTIR: Measurements were preformed on a Nicolet Fourier transform infra-red spectrometer (510) equipped with Spectra-Tech Inc. diffuse reflectance accessory. The resolution was $4 \mathrm{~cm}^{-1}$. All samples were $8 \%$ wt of sample in $\mathrm{KBr}$ matrix. Typically 100 scans were performed for each spectrum. All spectra are normalized Kubelka Munk plots. Lead ions were added as $\mathrm{Pb}\left(\mathrm{NO}_{3}\right)_{2}$. Atomic absorption: The concentration of unreacted lead ions in the solution was measured with Buck Scientific 200A Atomic Absorption Spectrophotometer. Cyclic voltametry: The redox potentials of lead-cysteine complex was obtained by cyclic voltametry where glassy carbon was used as working electrode, SCE as reference electrode, $10^{-2} \mathrm{M} \mathrm{KCl}$ as supporting electrolyte, and the $\mathrm{Ar}$ was bubbled through solutions. The potentials were scanned from $0.0 \mathrm{~V}$ to $-1.4 \mathrm{~V}$ vs. SCE and back.

\section{RESULTS AND DISCUSSION}

Characterization of unmodified and modified $\mathrm{TiO}_{2}$ catalysts

Electron - hole pairs generated during the illumination of $\mathrm{TiO}_{2}$ particles (eq. 1) can be 
exploited for various redox processes. Conduction band electrons that have the potential of -0.3 $\mathrm{V}$ (vs NHE) at $\mathrm{pH} 3^{15}$ are trapped on the particle surface in about 30 picoseconds and valence band holes with potential of $+2.9 \mathrm{~V}$ at $\mathrm{pH} 3$ are trapped in the hundred nanosecond range. ${ }^{16}$ As the energy levels of the surface traps lie within the band gap, the actual reduction and oxidation properties of photogenerated charges are reduced and are dependent on the redox potential of surface trapping sites. EPR investigations of surface trapping sites in colloidal $\mathrm{TiO}_{2}$ suggests that electrons are trapped at metal centers $\left(\mathrm{Ti}^{3+}\right)$, while the holes are trapped on the surface $\mathrm{OH}$ groups as a $\left(\mathrm{TiO}_{2}\right)_{\mathrm{n}} \mathrm{Ti}(\mathrm{IV}) \mathrm{O} \cdot$ radical intermediate. ${ }^{13,17}$

$$
\begin{aligned}
& \mathrm{e}^{-}+\left(\mathrm{TiO}_{2}\right)_{\mathrm{n}} \mathrm{Ti}(\mathrm{IV})-\mathrm{OH} \rightarrow\left(\mathrm{TiO}_{2}\right)_{\mathrm{n}} \mathrm{Ti}(\mathrm{III})_{\mathrm{x}}-\mathrm{OH} \\
& \mathrm{h}^{+}+\left(\mathrm{TiO}_{2}\right)_{\mathrm{n}} \mathrm{Ti}(\mathrm{IV})-\mathrm{OH} \rightarrow\left(\mathrm{TiO}_{2}\right)_{\mathrm{n}} \mathrm{Ti}(\mathrm{IV})-\mathrm{O} \cdot+\mathrm{H}^{+}
\end{aligned}
$$

where $\left(\mathrm{TiO}_{2}\right)_{\mathrm{n}}$ represents bulk material. The photoinduced EPR signal consists of the oxygen radical signal composed of an anisotropic $g$ tensor with $g_{z}=2.007, g_{y}=2.014$ and $g_{x}=2.024^{13,17}$ and the signals from trapped electrons, of $\mathrm{Ti}^{3+}$ in the bulk lattice $(\mathrm{g}=1.988)$, and of $\mathrm{Ti}^{3+}$ at the surface with $g=1.970$. If

We have found that in the presence of the tridentate ligand cysteine the characteristic oxygen radical signal in EPR spectrum disappears, and an axially symmetrical, lattice defect type EPR signal with $g=2.004$ is observed. ${ }^{18}$ These results suggest that cysteine is strongly bound to a colloid surface and passivates the surface states which act as hole traps. In this case only two components of the g-tensor with $\mathrm{g}=2.004$ and a shoulder at $\mathrm{g}=2.030$ were observed. This signal can be attributed to either of formation of oxygen centered radical with tetragonal symmetry $\left(\mathrm{O}_{\text {latt }}, \mathrm{g}_{\mathrm{x}}=\mathrm{g}_{\mathrm{y}}\right)^{19}$, or a C-centered radical of cysteine. ${ }^{20}$ Infrared spectroscopy (Figure 1) of a dried colloid sample suggests also that the cysteine is bound to $\mathrm{TiO}_{2}$ particles at $\mathrm{pH} 4$ with a

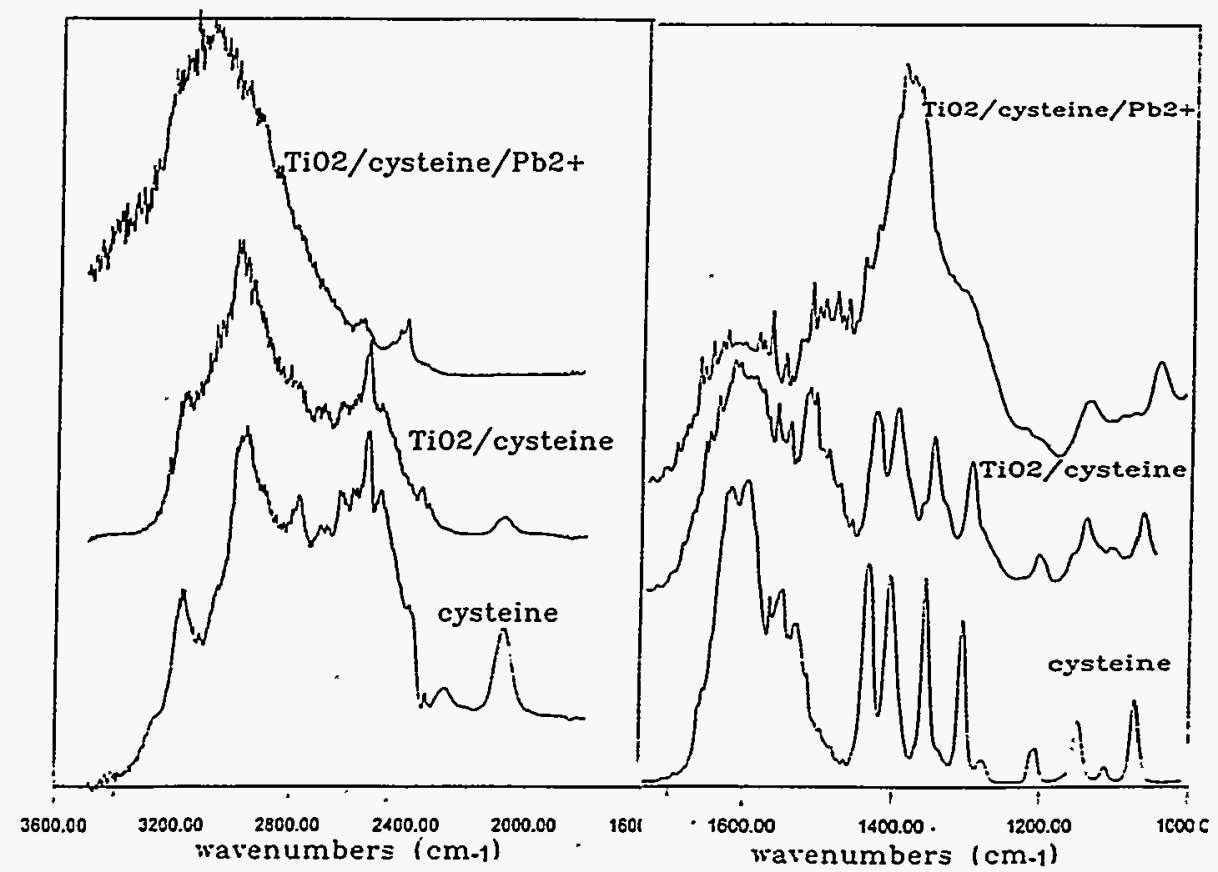

Figure 1. Cysteine adsorption on $50 \AA \mathrm{TiO}_{2}$ colloid: Infrared spectra of dried samples of (bottom) $0.1 \mathrm{M}$ cysteine at $\mathrm{pH} 4$ (middle) $0.1 \mathrm{M}$ cysteine modified $0.3 \mathrm{M} \mathrm{TiO}_{2}$ colloid at $\mathrm{pH} 4$ (top) $0.1 \mathrm{M}$ cysteine modified $0.3 \mathrm{M} \mathrm{TiO}_{2}$ in the presence of $0.1 \mathrm{M} \mathrm{Pb}\left(\mathrm{NO}_{3}\right)_{2}$ at $\mathrm{pH} 4$. 
carboxyl group. The spectrum of cysteine modified $\mathrm{TiO}_{2}$ (Figure 1, middle) was composed of characteristic carboxylic acid salt modes $\left(1520\right.$ and $\left.1350 \mathrm{~cm}^{-1}\right)$, while a broad carboxylic acid dimer band (centered around $3000 \mathrm{~cm}^{-1}$ ) and antisymmetric stretching of $C=O$ band $\left(1610 \mathrm{~cm}^{-1}\right)$ have decreased. These results indicate that cysteine is bound to a surface $\mathrm{Ti}$ atom through carboxyl group with formation of the corresponding salt (see scheme). As oxygen is covalently linked to the lattice, it can easily accept the photogenerated hole and transfer it to a cysteine molecule. Indeed, we found that at $200 \mathrm{~K}$ electron transfer process occurs and the holes are transferred from $\mathrm{TiO}_{2}$ particle to a cysteine molecule and a sulfur-centered radical is formed

$$
\begin{aligned}
& \mathrm{h}^{+}+\left(\mathrm{TiO}_{2}\right)_{\mathrm{n}} \mathrm{Ti}(\mathrm{IV})-\mathrm{O}_{2} \mathrm{C}-\mathrm{CH}\left(\mathrm{NH}_{3}{ }^{+}\right) \mathrm{CH}_{2} \mathrm{SH}- \\
& -\left(\mathrm{TiO}_{2}\right)_{\mathrm{n}} \mathrm{Ti}(\mathrm{IV})-\mathrm{O}_{2} \mathrm{C}-\mathrm{CH}\left(\mathrm{NH}_{3}{ }^{+}\right) \mathrm{CH}_{2} \mathrm{~S} \cdot+\mathrm{H}^{+}
\end{aligned}
$$

meanwhile EPR signal of $\mathrm{TiO}_{2}$ colloid itself at $200 \mathrm{~K}$ was not observed. ${ }^{18}$ The redox potential for the oxidation of cysteine into a sulfur radical intermediate requires the potential of hole to be more positive then $+0.92 \mathrm{~V}$ vs. NHE. ${ }^{21}$ The sulfur centered cysteine radicals most probably undergo dimerization with free cysteine molecules and form cystine radical (RSSR ${ }^{-}, \mathrm{E}^{\circ}\left(\mathrm{RSSR}^{-}\right.$ $\left.\cdot / 2 \mathrm{RS}^{-}\right)=+0.65 \mathrm{~V}$ vs. $\left.\mathrm{NHE}\right)^{20}$ at room temperature. Illumination of a cysteine modified $\mathrm{TiO}_{2}$ colloid thus results in oxidation of cysteine molecules into cystine and accumulation of trapped electrons.

The presence of cysteine affects the electron trapping sites also. While the narrow EPR signal at 1.988 due to the electron trapping associated with the $\mathrm{Ti}^{3+}{ }_{\text {latt }}$ centers in the particle interior ${ }^{17}$ is not affected with the addition of cysteine, surface trapped electrons become trapped on two distinct surface trapping sites (A and B). It should be noted that the signal from untrapped, conduction band electrons is too broad to be observed. The two asymmetric EPR signals obtained for trapped electrons $\left(\mathrm{g}_{\mathrm{A}}=1.970, \mathrm{~g}_{\mathrm{B}}=1.950\right)$ in the presence of cysteine are the same as those previously reported in the presence of methanol. ${ }^{22}$ It was shown previously that these two signals belong to two distinct species which decay with different kinetics at different temperatures. ${ }^{22}$ The appearance of a new trapping site for electrons is probably the consequence of the different coordination of surface titanium atoms when chemisorption of oxygen containing adsorbates takes place.

\section{Photodeposition of lead}

Upon addition of lead ions into solutions with surface modified $\mathrm{TiO}_{2}$ colloid, a new complex of cysteine with heavy metal was observed with $\mathbb{R}$ spectroscopy. Lead ions bind with cysteine molecule in a strong $1: 1$ complex $(\mathrm{pK}=11.6)$ in which cysteine acts as a tridentate ligand. ${ }^{23} \mathrm{IR}$ spectroscopy of dried cysteine modified $\mathrm{TiO}_{2}$ colloid containing lead ions also suggests that lead is chelated with cysteine ligand with only the carboxyl and mercapto groups. In the $\mathbb{R}$ spectrum new bands characteristic for the stretching vibration of linear O-C-O vibration at 2400 and $1380 \mathrm{~cm}^{-1}$ was detected (Figurre 1, top). The carboxyl group bridges Ti and $\mathrm{Pb}$ ions (Ti-O-C-O-Pb), and in this way $\mathrm{Pb}$ becomes covalently linked to the particle surface (see scheme), and a continuation of the particle lattice. Illumination of this system did not result in the formation of sulfur centered radical at $200 \mathrm{~K}$ probably because the lone pair of electrons of sulfur that participate in oxidation are bound to the lead ion. However, a relatively intense EPR signal probably due to the presence of axial symmetrical lattice defect associated with trapped holes in surface modified colloid at $8 \mathrm{~K}\left(\mathrm{O}^{-} \cdot\right.$ latt $)$ was again observed (Figure 2). The EPR signal for 
particles responsible for lead reduction? There are four ways that cysteine can modify the properties of the systems which would lead to the reduction of $\mathrm{Pb}^{2+}$ ions: (1) electron accumulation (2) strong adsorption of lead ions (3) modification of lead ion reduction potentials after complexation and (4) the modification of the redox properties of $\mathrm{TiO}_{2}$ itself.

(1)We have found that illumination of cysteine modified $\mathrm{TiO}_{2}$ leads to the accumulation of trapped electrons, as the holes are effectively scavenged by cysteine molecules which are probably oxidized to cystine. In this way accumulated electrons can be used for subsequent simultaneous injection of

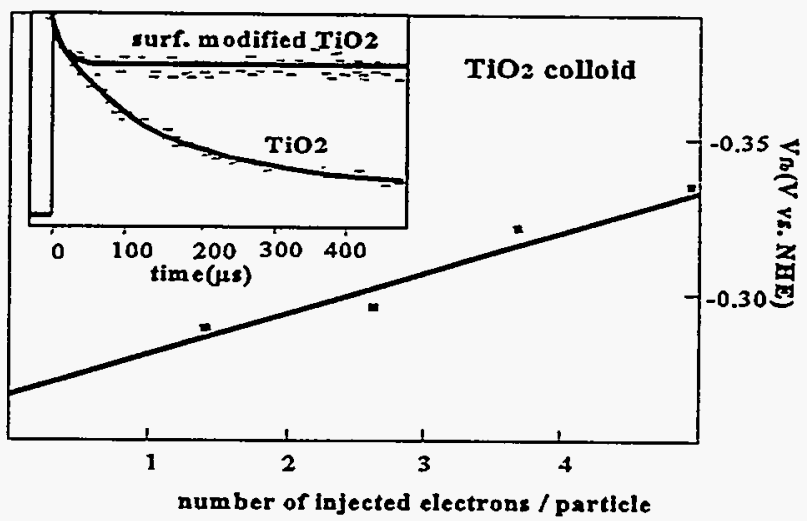

Figure 3. Dependance of the Fermi level of $\mathrm{TiO}_{2}$ particles on the number of injected electrons from monovalent cation radical of methyl viologen zwitter ion. On the insert are shown oscilloscope traces obtained (a) in $0.08 \mathrm{M} \mathrm{TiO}_{2}$ and (b) in $0.07 \mathrm{M} \mathrm{TiO}{ }_{2}$ colloids modified with 2mercaptopropionate ions. multiple charges and the reduction of lead does not proceed via a one electron reduction process $\left(\mathrm{E}^{\mathrm{O}}\left(\mathrm{Pb}^{2+} / \mathrm{Pb}^{+}\right)=-1.0 \mathrm{~V}\right.$ vs NHE), but a two electron reduction of lead ions with much lower reduction potential becomes possible. (2) We have also found that there is stronger adsorption of $\mathrm{Pb}^{2+}$ ions on cysteine modified particles compared to neat $\mathrm{TiO}_{2}$ colloids ${ }^{24}$ so that the efficiency of electron transfer from the $\mathrm{Ti}^{3+}$ centers to cysteine bridged lead ions is significantly enhanced.

(3) From cyclic voltamograms we have found that the redox potential for two electron transfer process in $\mathrm{Pb} /$ cysteine molecules becomes more negative $\left(\mathrm{E}^{\mathrm{O}}\left(\mathrm{Pbcys}^{+} / \mathrm{Pb}^{\mathrm{O}}\right.\right.$ cys $\left.{ }^{-}\right)=-0.252 \mathrm{~V}$ vs. NHE compared to $\left.\mathrm{E}^{\circ}\left(\mathrm{Pb}^{2+} / \mathrm{Pb}^{\mathrm{O}}\right)=-0.126\right)$. The flat band potential of $\mathrm{TiO}_{2}\left(\mathrm{~V}_{\mathrm{fb}}\right)$ which describes the potential of the electron at the $\mathrm{TiO}_{2}$ /liquid interface is given by 15

$$
\mathrm{V}_{\mathrm{fb}}=-0.05+(-0.059) \mathrm{pH}
$$

The reducing ability of the electrons at $\mathrm{pH} 4$ is -0.3 a value that only slightly exceeds the redox potential for the reduction of $\mathrm{Pb} /$ cysteine complex. However, at $\mathrm{pH} 3$ where the potential of the Fermi level is less negative, precipitation of metallic lead was again observed. This result indicates that the position of the $\mathrm{TiO}_{2}$ Fermi level also changed.

(4) Thus, we have examined the change of the position of the Fermi level in modified and unmodified $\mathrm{TiO}_{2}$ colloids with pulse radiolysis technique ${ }^{25}$ and found that the position of the Fermi level in modified colloids shifts by at least negative $0.10 \mathrm{~V}$. In this experiment the monovalent zwitter radical ion of methyl viologen $Z W^{-}\left(E^{\circ}\left(Z W^{0} / Z W\right)=-0.443 \mathrm{~V}\right.$ vs NHE) formed during radiolysis process injects the charge into unmodified $\mathrm{TiO}_{2}$ colloid until equilibrium is establishes according to the equation

$$
\mathrm{V}_{\mathrm{fb}}=\mathrm{V}\left(\mathrm{ZW}^{0} / \mathrm{ZW}^{-}\right)=-0.443+\mathrm{RT} / \mathrm{zF} \log \left[\mathrm{ZW}^{0}\right] /\left[\mathrm{ZW}^{-}\right]
$$

where the position of the Fermi level is equal to the potential of the redox couple.in the solution. The position of the Fermi level for unmodified colloid was found to be -0.265 at $\mathrm{pH} 3.5$ for the 
trapped electrons did not change at $8 \mathrm{~K}$ after addition of lead ions

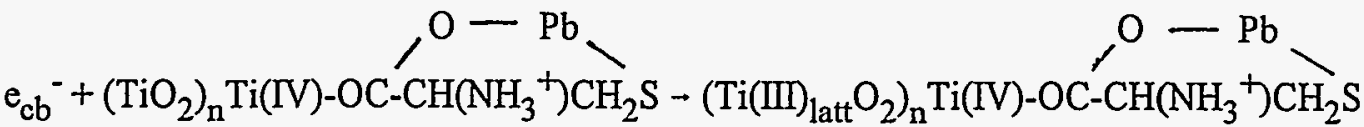

$$
\begin{aligned}
& \text { or }\left(\mathrm{TiO}_{2}\right)_{\mathrm{n}} \mathrm{Ti}(\mathrm{III})_{\text {surf }} \mathrm{OC}-\mathrm{CH}\left(\mathrm{NH}_{3}{ }^{+}{ }^{-} \mathrm{CH}_{2} \mathrm{~S}\right.
\end{aligned}
$$

At $120 \mathrm{~K}$, however, the relative intensity of the signal for lattice type $\mathrm{Ti}^{3+}$ trapped electrons decreases, and surface trapped $\mathrm{Ti}^{3+}$ electrons with $\mathrm{g}=$ 1.970 (A) and $\mathrm{g}=1.950$ (B) have increased.

$$
\operatorname{Ti}(\mathrm{III})_{\text {latt }}-\operatorname{Ti}(\mathrm{III})_{\text {surf }}
$$

These results indicate that the electron transfer from the interior of the particle to surface trapped states occurs first indicating the lowest activation energy for intraparticle charge transfer reactions. When the temperature was raised to $200 \mathrm{~K}$ the signal for the surface trapped electrons A disappeared while the signal for surface trapped electrons B increased four times relative to the trapped hole signal.

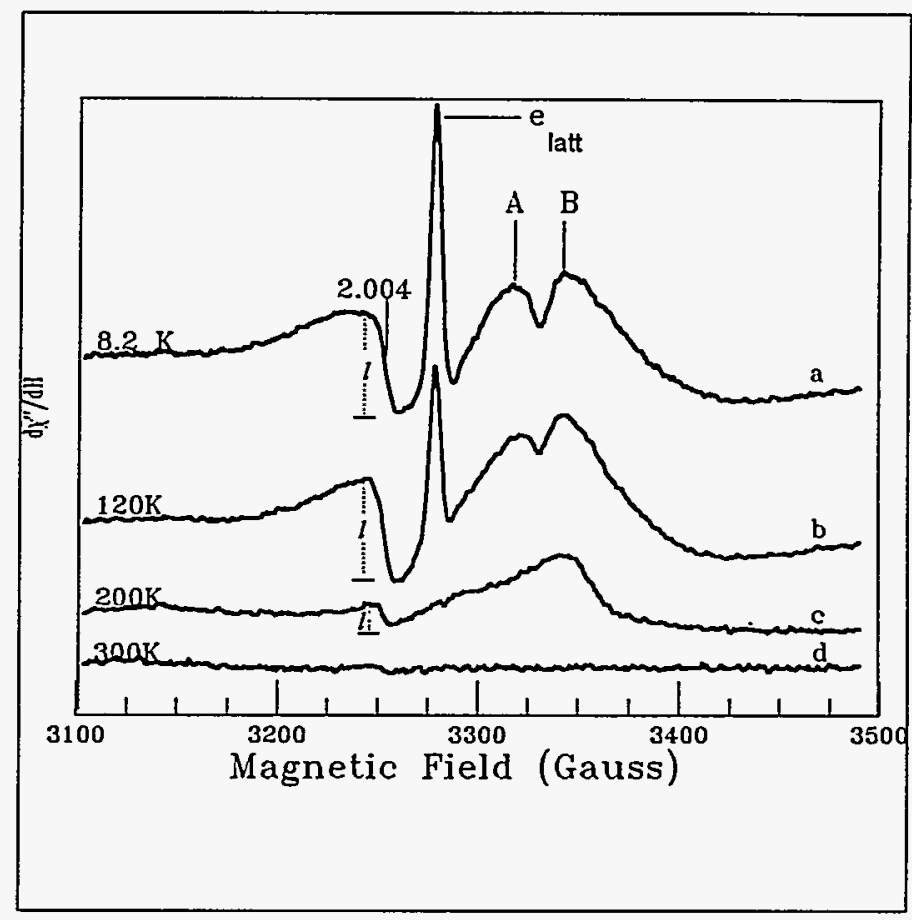

Figure 2. EPR $\left(X\right.$-band) spectra of degassed aqueous $\mathrm{TiO}_{2}$ colloids $(0.2 \mathrm{M})$ in the presence of $(0.1 \mathrm{M})$ cysteine and $\mathrm{Pb}^{2}$ ions $\left(5 \times 10^{-2} \mathrm{M}\right)$ irradiated with $308 \mathrm{~nm}$ excimer laser at 77 $\mathrm{K}$ recorded at different temperatures.

$$
\operatorname{Ti}(\text { III) })_{\text {surf A }} \rightarrow \operatorname{Ti}(\text { III })_{\text {surf B }}(6)
$$

These results indicate that the transition from surface state $A$ to surface state $B$ is thermodynamically favorable. Upon increasing the temperature to room temperature for several minutes, all photogenerated electrons are scavenged by metal ions,

$$
\begin{aligned}
& \left.2 \mathrm{Ti}(\mathrm{III})_{\text {latt }} \mathrm{O}_{2}\right)_{\mathrm{n}} \mathrm{Ti}(\mathrm{IV})-\mathrm{OC}-\mathrm{CH}\left(\mathrm{NH}_{3}{ }^{+} \mathrm{CH}_{2} \mathrm{~S}-\right. \\
& -2\left(\mathrm{TiO}_{2}\right)_{\mathrm{n}} \mathrm{Ti}(\mathrm{III})_{\text {surf }} \mathrm{OC}^{-} \mathrm{CH}\left(\mathrm{NH}_{3}{ }^{+} \mathrm{CH}_{2} \mathrm{~S}-2\left(\mathrm{TiO}_{2}\right)_{\mathrm{n}} \mathrm{Ti}(\mathrm{IV})-\mathrm{O}_{2} \mathrm{C}-\mathrm{CH}\left(\mathrm{NH}_{3}{ }^{+}\right) \mathrm{CH}_{2} \mathrm{SH}+\mathrm{Pb}^{\circ}\right.
\end{aligned}
$$

and the metal lead was observed to precipitate.

The reduction of $\mathrm{Pb}^{2+}$ ions in $\mathrm{TiO}_{2}$ aqueous suspensions was not observed previously. ${ }^{11,12}$. The following question arises. Thus how are cysteine molecules on $\mathrm{TiO}_{2}$ 
zero charge injected into colloid (Figure 3). On the other hand, $\mathrm{ZW}^{-}$cannot inject the charge into the surface modified $\mathrm{TiO}_{2}$. Thus the position of the Fermi level must be more negative then the redox potential of the solution of the highest concentration of $\mathrm{ZW}^{-}$which was investigated $\left(\mathrm{V}_{\mathrm{fb}}\right.$ $<-0.372 \mathrm{~V}$ vs NHE). The shift of the bands to the negative potentials is probably the consequence of strong adsorption of the carboxyl group on the colloid surface. It has been reported previously that strong adsorption of the negative counter ions on the electrode surface shifts the $V_{\mathrm{fb}}$ to more negative values (e.g. adsorption of chalcogenide ions ${ }^{26}$ or thiols ${ }^{27}$ on IIVI semiconductors), or adsorption of $\mathrm{OH}^{-}$in alkaline solution on oxide semiconductors shifts $\mathrm{V}_{\mathrm{fb}}$ in cathodic direction according to the eq. (8). Strong adsorption of carboxyl compounds would build up negative charges on the semiconductor surface by electrons from the reducing species in the solution (cysteine). Thus, we expect that the energy bands of cysteine modified $\mathrm{TiO}_{2}$ would also be strongly shifted to negative potentials, as was observed in our pulse radiolysis experiments.

Therefore, it appears that reduction of lead on cysteine modified colloidal solutions of $\mathrm{TiO}_{2}$ is likely to be a consequence of a combination of all four factors which are considered to influence redox properties of lead/cysteine $/ \mathrm{TiO}_{2}$ system.

\section{Photodeposition of Lead in the Presence of Current Doubling Agent- Conversion of Holes into Reducing Species}

We have found that the yield of trapped electrons is enhanced after addition of methanol (Figure 4), which is an effective hole scavenger $\left(\mathrm{E}^{\mathrm{O}}\left(\mathrm{CH}_{3} \mathrm{OH} / \cdot \mathrm{CH}_{2} \mathrm{OH}\right)=+1.2 \mathrm{~V}\right)^{28}$. It has been shown previously that electrochemical oxidation of methanol results in formation of electron donating species $\left(\mathrm{E}^{\circ}\left(\cdot \mathrm{CH}_{2} \mathrm{OH} / \mathrm{CH}_{2} \mathrm{O}\right)=-0.95 \mathrm{~V}\right)^{7}$. The net effect is that from one photon two electrons are formed, and that phenomenon is known in electrochemistry as current doubling effect. ${ }^{29}$ Trapped electrons in $\mathrm{TiO}_{2}$ have enough potential to reduce lead ions in two electron reduction process.

In the presence of
methanol EPR signal of lead/cysteine modified $\mathrm{TiO}_{2}$ colloid at $8.2 \mathrm{~K}$ (Figure 4a) was composed of a partially obscured triplet with line separation of $18 \mathrm{G}$, a doublet with $130 \mathrm{G}$ line separation, arising from methanol radical $\left(\cdot \mathrm{CH}_{2} \mathrm{O}(\mathrm{H})\right)$ and formyl radical $(\cdot \mathrm{CHO}),{ }^{30,13}$ respectively, and the signals associated with trapped electrons, of $\mathrm{Ti}^{3+}$ in the bulk lattice $(\mathrm{g}=1.988)$, and of $\mathrm{Ti}^{3 .+}$ at the surface with $\mathrm{g}=1.970$ and

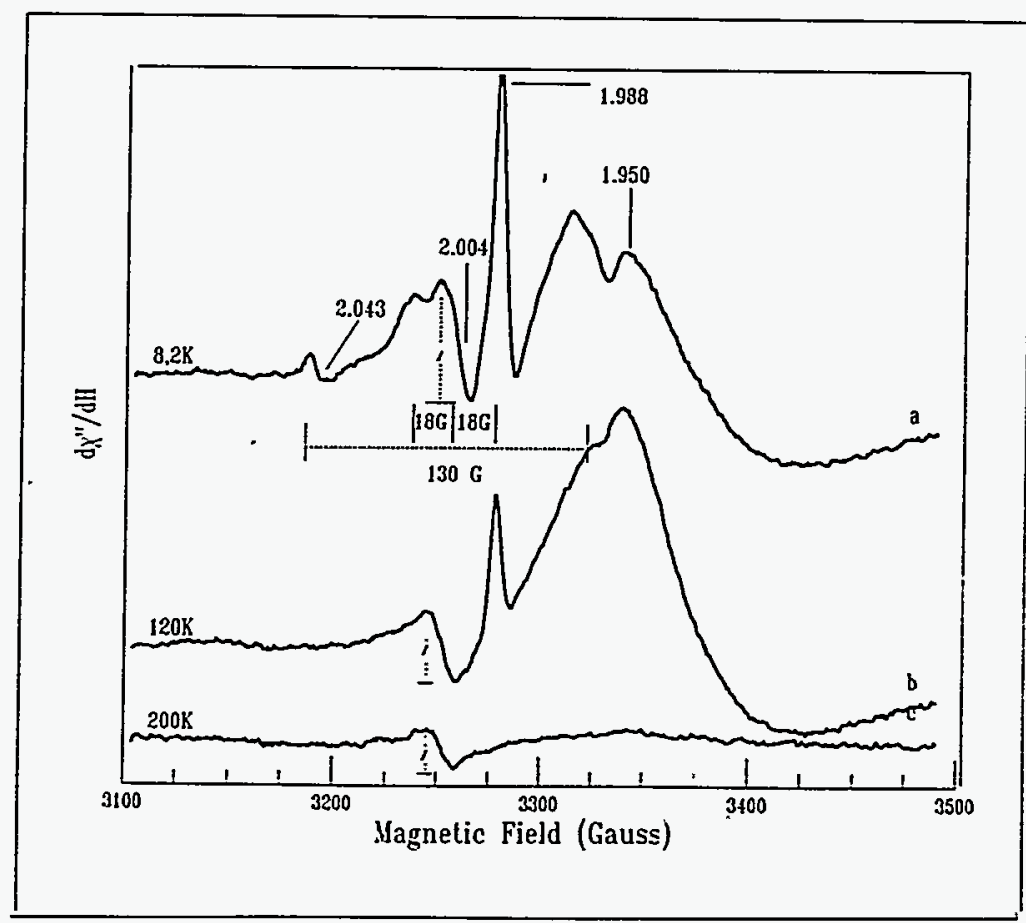

Figure 4. EPR (X-band) spectra of degassed aquaous $\mathrm{TiO}_{2}$ colloids $(0.2 \mathrm{M})$ in the presence of $(0.1 \mathrm{M})$ cysteine and $\mathrm{Pb}^{2+}$ ions $\left(5 \times 10^{-2} \mathrm{M}\right)$ and methanol (1M) irradiadiated with $308 \mathrm{~nm}$ excimer laser at $77 \mathrm{~K}$ recorded at different temperatures. 
1.950. This result indicates that immediately after charge separation the holes are transferred to adsorbed methanol which is oxidized to the methanol radical

$$
\begin{gathered}
\mathrm{h}^{+}+\left(\mathrm{TiO}_{2}\right)_{\mathrm{n}} \mathrm{Ti}(\mathrm{IV})-\mathrm{O} . . \mathrm{HOCH}_{3} \rightarrow \\
\left(\mathrm{TiO}_{2}\right)_{\mathrm{n}} \mathrm{Ti}(\mathrm{IV})-\mathrm{O} . . . \mathrm{HOCH}_{2} \cdot+\mathrm{H}^{+}
\end{gathered}
$$

where methanol forms a hydrogen bound with surface oxygens. (The most probable site for hydrogen bond formation is with the oxygen that bridges two surface Ti(IV) atoms and has a free electron pair, since the majority of surface $\mathrm{OH}$ groups are replaced with cysteine molecules ${ }^{31}$ ). As photogenerated holes are transferred to methanol rather then to cysteine molecules $\left(E^{\circ}\left(\mathrm{RSSR}^{-} \cdot / 2 \mathrm{RS}^{-}\right)=+0.65 \mathrm{~V}\right)$, it can be concluded that after complexation with lead ions cysteine has lost its oxidizing abilities and has become anelectron accepting species. This explanation is supported by the fact that illumination of the cysteine modified $\mathrm{TiO}_{2}$ (without lead ions) in the presence of methanol resulted in the formation of the sulfur centered radical of cysteine (Figure 5).

The large negative potential of the methanol radical induces electron injection at $120 \mathrm{~K}$ into colloidal $\mathrm{TiO}_{2}$ with formation of surface trapped electrons

$$
\left(\mathrm{TiO}_{2}\right)_{\mathrm{n}} \mathrm{Ti}(\mathrm{IV})-\mathrm{O} . . . \mathrm{HOCH}_{2} \cdot \rightarrow\left(\mathrm{TiO}_{2}\right)_{\mathrm{n}} \mathrm{Ti}(\mathrm{III})-\mathrm{O}+\mathrm{OCH}_{2}+\mathrm{H}^{+}
$$

Consequently the yield of electrons is doubled. This is demonstrated in Figure $4 \mathrm{~b}$ where the signal intensity for $\mathrm{Ti}(\mathrm{Im})_{\text {surf }}$ at $\mathrm{g}=1.50$ approximately doubles compared to the signal in Figure $4 \mathrm{a}$. This spectrum disappears at $200 \mathrm{~K}$ due to the reduction of $\mathrm{Pb}^{2+}$. It should be noted that direct reduction of $\mathrm{Pb}^{2+}$ ions was not observed in homogeneous solutions due to the negative potential of one electron reduction of lead ions. Direct reduction of $\mathrm{Pb}^{2+}$ by $\mathrm{CH}_{2} \mathrm{OH}$ on colloidal $\mathrm{TiO}_{2}$ was not observed.

\section{Conclusion}

On the basis of these result we propose a reaction scheme that describes the mechanism of lead reduction on cysteine modified colloids in the presence of a current doubling agent (Scheme 1). It can be seen from the scheme that absorption of one photon of light in our case resulted in the formation of one neutral lead molecule as both the electron and holes are used for the reduction process. The quantum yield in this case is twice as large as one would obtain with unmodified catalyst in the absence of methanol. 


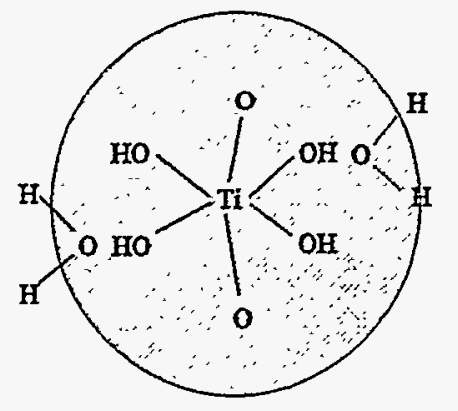

$\mathrm{TiO}_{2}$

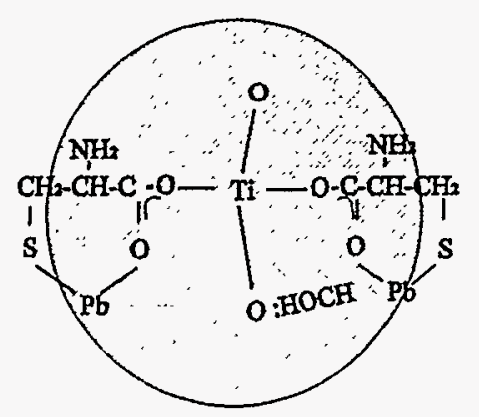

$\mathrm{TiO}_{2} /$ cysteine $/ \mathrm{Pb}^{2+}$ +methanol

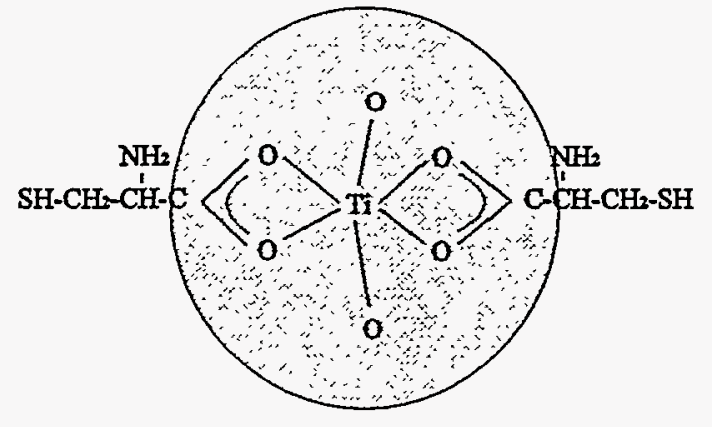

$\mathrm{TiO}_{2}$ /cysteine

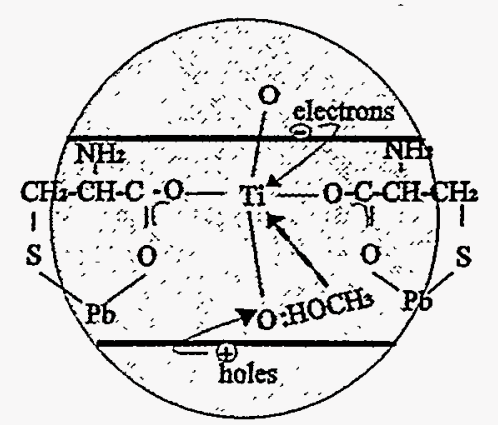

hv $\rightarrow \mathrm{Ti}(\mathrm{II})+\mathrm{O}$...HOCं $\mathrm{H}_{2}$ $-\underset{-\rightarrow \mathrm{Ti}}{ }(\mathrm{II})+\mathrm{CH}_{2} \mathrm{O}$

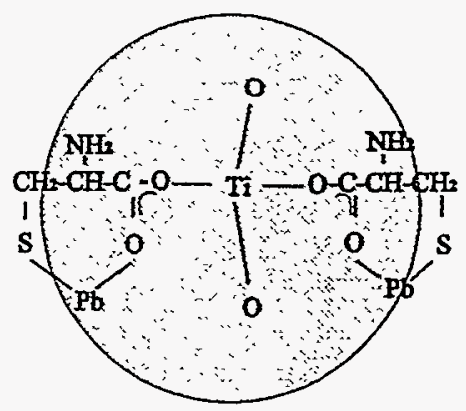

$\mathrm{TiO}_{2} /$ cysteine/ $/ \mathrm{Pb}^{2+}$

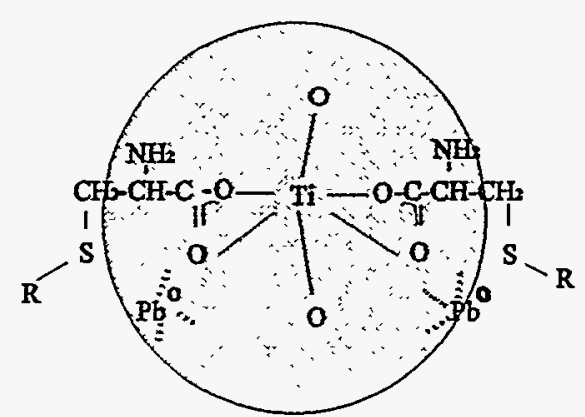

electron transfer $\rightarrow$

$\mathbf{P b}^{\mathbf{0}}$

\section{Aknowledgement}

The authors want to thank $\mathrm{D}$. Meisel and D. Lawless for the pulse radiolysis measurements and D. Gosztola for performing cyclic voltametry measurements. Also we appreciate useful discussions with N. Meshkov, R.W. Peters and J.M. Wu. This work was supported by the U.S. Department of Energy, Office of Basic Energy Sciences, Division of Chemical Sciences under contract W-31-109-Eng-38.

\section{REFERENCES}

1. For comprehensive reviews see Serpone, N., Pelizzetti E., Eds, 1989. "Photocatalysis Fundamentals and Applications", John Willey and Sons, New York.

2. Fox, M.A., 1987. Top. Curr. Chem., 72: 142.

3. Ollis, D.F., 1985. Environ. Sci. Technol., 19: 480.

4. Boeck, R.L., 1986. Anal. Chem., 58: 274A.

5. Rader, W.A., Spaulding, J.E., 1979. in "Toxicity of heavy metals in the Environment", Part 2, Oehme, F.W. Ed., Marcel Dekker Inc., New York, pp. 669.

6. Josephson, J., 1986. Environ. Sci. Technol., 20: 23.

7. Breitenkamp, M., Henglein, A., Lilie, J., 1976., Ber. Bunsebges. Phys. chem., 80: 973.

8. Al-Ekabi, H., Serpone, N., Pelizzetti, E., Minero, C., Fox, M.A., Draper, R.B., 1989.

Langmuir, $5: 250$.

9. Gerisher, H., Heller, A., 1992., J. Electrochem. Soc., 139: 113. 
10. Fox, M.A., 1983., Acc. Chem. Res., 16: 314.

11. Lawless, D., Res, A., Harris, R., Serpone, N., 1990. Chem. Ind. (Milan), 72: 139.

12. Tanaka, K.,Harada, K., Murata, S., 1986, Sol. Energy 36: 159.

13. Micic, O.I., Zhang, Y., Cromack, K.R., Trifunac, A.D., Thurnauer, M.C., 1993. J..Phys.Chem., 97: 7277.

14. Thompson, R.C., 1984., Inorg. Chem., 23: 1794.

15. Ward, M.D., White, J.R., Bard, A.J., 1983., J. Am. Chem. Soc., 105: 27.

16. Rothenberg, G., Moser, J., Gratzel, M., Serpone, N., Sharma, D.K., 1985., J. Am. Chem. Soc., 107: 8054.

17. Howe, R.F., Gratzel, M., 1985., J. Phys. Chem., 89: 4495; Howe, R.F., Gratzel, M., 1987, J.Phys.Chem., 91: 3906.

18. Ostafin, A.E., Micic, O.I., Sobelko, J.J., Zang, Y., Tiede, D.M., Thurnauer, M.C., to be published.

19. Schlick, S., Kevan, L., 1977., J. Phys. Chem., 81: 1083.

20. Henriksen, T., 1962., J. Chem. Phys., 16: 1258.

21. Surdhar, P.S., Armstrong, D.A., 1986. J.Phys. Chem., 90: 5915.

22. Micic, O.I., Zhang, Y., Cromack, K.R., Trifunac, A.D., Thurnauer, M.C., 1993.

J.Phys.Chem., 97: 13284.

23. Li, N.C., Manning, R.A., 1955. J. Am. Chem. Soc., 77: 5225; Martell, A.E., Smith, R.M., 1974, "Critical Stability Constants", Vol.1: Amino Acids, Plenum Press, New York, pp.47.

24. Peters, R.W., Wu, J.M., Meshkov, N., Thurnauer, M.C., Ostafin, A.E., 1994, $5^{\text {th }}$

International Symposium on "Chemical Oxidation:Technology for the Nineties", Nashiville, TN, February 15-17.

25. Dimitrijevic, N.M., Savic, D., Micic, O.I., Nozik, A.J., 1984.J.Phys. Chem., 88:4278.

26. Ellis, A.B., Kaiser, S.W., Bolts, J.M., Wrighton, M.S., 1977. J. Am. Chem. Soc., $99:: 2839$.

27. Natan, M.J., Thackeray, J.W., Wrighton, M.S., 1986. J.Phys.Chem., 90: 4089.

28. Lilie, J., Beck, G., Henglein, A., 1971. Ber. Bunsenges. Phys. Chem., 75: 843.

29. Nogami, G., Kennedy, J.H. 1989., J. Electrochem. Soc., 136: 2583.

30. Sullivan, P.J., Koski, W.S., 1963, J. Am. Chem. Soc., 85: 384; Livingston, R., Zeides, H., 1966, J. Chem. Phys.,44:1245.

31. Primet, M., Pichat, P., Mathieu, M., 1971. J.Phys. Chem., 75: 1221. 